\title{
Variations of Near Surface Energy Balance Caused by Land Cover Changes in the Semiarid Grassland Area of China
}

\author{
Qun'ou Jiang, ${ }^{1}$ Chengcai Tang, ${ }^{2}$ Enjun Ma, ${ }^{3}$ Yongwei Yuan, ${ }^{4}$ and Wei Zhang' \\ ${ }^{1}$ School of Soil and Water Conservation, Beijing Forestry University, Beijing 100038, China \\ ${ }^{2}$ School of Tourism Management, Beijing International Studies University, Beijing 100024, China \\ ${ }^{3}$ School of Mathematics and Physics, China University of Geosciences (Wuhan), Wuhan 430074, China \\ ${ }^{4}$ Faculty of Resources and Environmental Science, Hubei University, Wuhan, Hubei 430062, China \\ Correspondence should be addressed to Qun’ou Jiang; jiangqo.dls@163.com
}

Received 29 August 2013; Revised 11 October 2013; Accepted 23 December 2013; Published 27 February 2014

Academic Editor: Burak Güneralp

Copyright (C) 2014 Qun'ou Jiang et al. This is an open access article distributed under the Creative Commons Attribution License, which permits unrestricted use, distribution, and reproduction in any medium, provided the original work is properly cited.

\begin{abstract}
This study applies the Dynamics of Land System (DLS) model to simulating the land cover under the designed scenarios and then analyzes the effects of land cover conversion on energy flux in the semiarid grassland area of China with the Weather Research and Forecasting (WRF) model. The results indicate that the grassland will show a steadily upgrowing trend under the coordinated environmental sustainability (CES) scenario. Compared to the CES scenario, the rate of increase in grassland cover is lower, while the rate of increase in urban land cover will be higher under the rapid economic growth (REG) scenario. Although the conversion from cropland to grassland will reduce the energy flux, the expansion of urban area and decreasing of forestry area will bring about more energy flux. As a whole, the energy flux of near surface will obviously not change under the CES scenario, and the climate therefore will not be possible to be influenced greatly by land cover change. The energy flux under the REG scenario is higher than that under the CES scenario. Those research conclusions can offer valuable information for the land use planning and climate change adaptation in the semiarid grassland area of China.
\end{abstract}

\section{Introduction}

Climate change is a serious challenge faced by the international community, and the human-induced land cover change is increasingly recognized as having significant effect on the climate system [1-3]. The land surface change influences the climate through altering the exchange of energy and material between land surface and the overlying atmosphere $[4,5]$. In addition, the land cover conversion changes the regional water and heat balance which had great influence on the global ecological system [6-8]. Therefore, analysis on the temporal and spatial heterogeneity of surface energy caused by land cover changes cannot only provide support for simulation of regional energy flux distribution, but also make up for the defect in the remote sensing monitoring of spatial heterogeneity of near surface energy fluxes. In addition, the land cover change can significantly impact regional biogeochemical cycles [8-10]. Therefore, the quantitative estimation of the impact of land cover change on energy fluxes is one of the hot topics in current and future decades.

Since the mid-1970s, scholars studied the impact of deforestation, grassland degradation, desertification, irrigation, and other land cover changes by using the global and regional climate model patterns [11-14]. Pitman thought that land surface properties can significantly alter the energy transfer of near surface through changing the surface energy balance and distribution of land cover based on the analysis of observed data and numerical test [15]. Zheng et al. found that land cover changes can significantly alter the release of effective surface fluxes by the studies on the impact of land cover on climate using regional climate model [16]. According to those researches, it can be concluded that the land use/cover change alters the land roughness, soil hydrological and thermal features, which lead to further change in the land surface energy balance, downward short wave radiation, sensible heat and latent heat, and so forth $[17,18]$. Lawrence and Chase found 


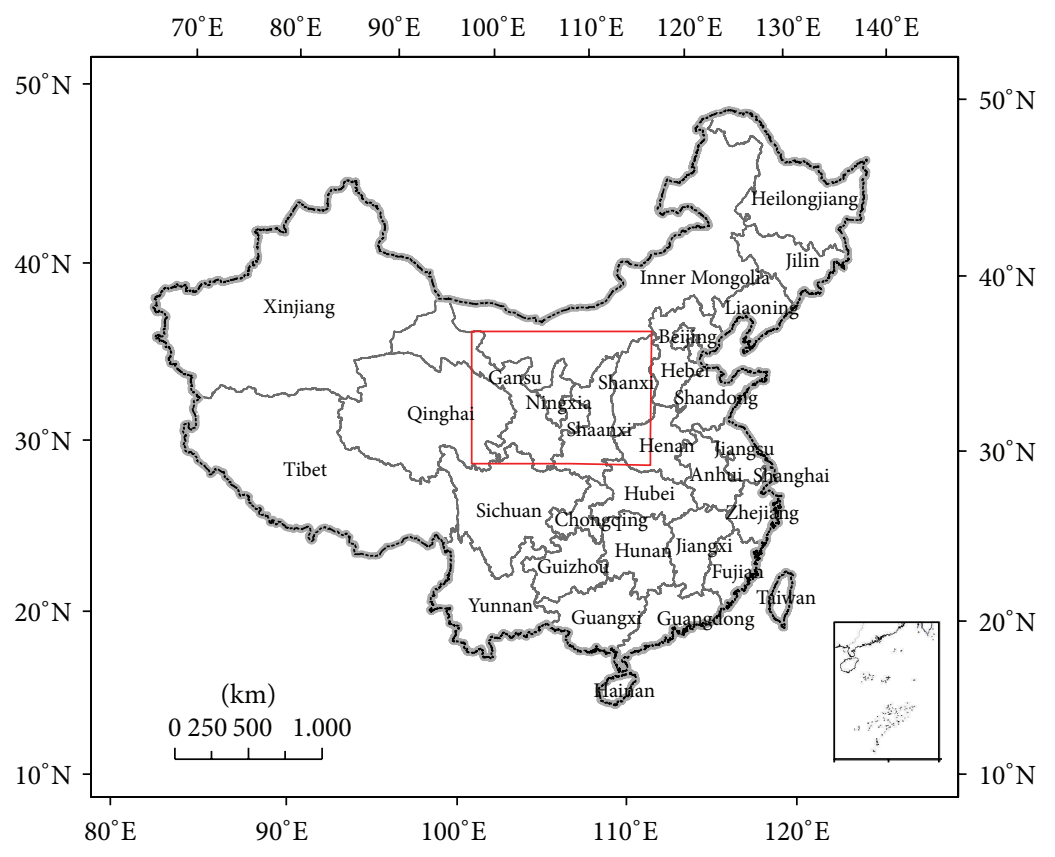

FIgURE 1: Location of study area.

that the climate effects of land cover are mostly caused by the water circulation changes which is mainly represented by reducing the evapotranspiration and increasing latent heat, and then the radiation changes $[19,20]$. Therefore, this study selects the latent heat and short-wave radiation as the index and analyzes the effects of land cover change on energy balance.

Loess Plateau is mainly located in the arid and semiarid area of China with a fragile ecological environment (Figure 1). Poor land use practices have resulted in the serious soil erosion, land degradation, desertification, and deterioration of the ecological environment [21]. To speed up the construction of ecological environment in Western China, the government had taken the policy of returning cropland to forestry area or grassland, which has achieved desirable results. It not only prevents the soil erosion and ecological environment degradation effectively, but also promotes the development of grass industry, animal husbandry, and agriculture industries after the policy is implemented comprehensively [22]. However, when we are concerned about the benefits of the policy of returning cropland to forestry area or grassland, it should be noted whether such large-scale land cover changes will impact the regional climate. Will it relieve the drought to some extent or make it more serious? Does it have effects on energy flux of near surface? Returning cropland to forestry area or grassland will continue in the next few decades to protect the ecological environment; therefore, the contribution of land cover changes to the energy flux of near surface becomes one of the significant issues [23, 24].

It is essential to quantify the effects of land cover changes on energy flux in the Loess Plateau for climate change adaptation and regional ecological environment construction. This study simulates the spatial distribution of land cover changes with the Dynamics of Land System (DLS) model, then it estimates the energy flux of near surface at a regional scale based on the principle of energy balance and similarity theory of boundary layers with the WRF model and finally explores the response mechanism of the temporal and spatial variation of surface energy flux to land cover changes. The results will provide scientific basis for the land use planning and climate change mitigation.

\section{Data Source and Handling}

2.1. Land Cover Data. Different communities have different types of land cover classification systems, and this study applies the classification system of USGS which includes 24 types of land cover. First, the land cover data with a spatial resolution of $1 \mathrm{~km}$ in 2010 are extracted from the remote sensing images, and the year 2010 is taken as the baseline year. Then two kinds of scenario, for example, coordinated environmental sustainability (CES) scenario, rapid economic growth (REG) scenario, and so forth, are designed. The land cover data during 2010-2050 are simulated by Dynamics of Land System (DLS) model based on the land demand estimated under the two scenarios. Finally, the $1 \mathrm{~km}$ resolution land cover data from 2010 to 2050 were resampled into $10 \mathrm{~km}$ resolution data according to the requirement of the WRF model.

2.2. Forcing Data. The forcing data needed in the WRF model, including wind field, surface air temperature, longwave radiation, and short-wave radiation, are derived from the dataset of the fifth phase of the Climate Model Intercomparison Project (CMIP5) which will be mostly relied on by the upcoming IPCC Fifth Assessment Report (AR5). CMIP5 
TABLE 1: Design of WRF model and relative description.

\begin{tabular}{|c|c|c|}
\hline WRF & Designation & Description \\
\hline Simulation period & 2010_01_01-2050_12_31 & \\
\hline Time resolution & Day & \\
\hline D01/02/03 land cover data & USGS & \\
\hline Microphysics parameterization scheme & WSM3 & $\begin{array}{l}\text { It includes water vapor, cloud water, rain, cloud ice, } \\
\text { snow, and cloud water. }\end{array}$ \\
\hline Long-wave radiation scheme & RRTM & $\begin{array}{l}\text { It uses preset tables to accurately represent long wave } \\
\text { processes due to water vapor, ozone, } \mathrm{CO}_{2} \text {, and trace } \\
\text { gases (if present) and accounts for cloud optical depth. }\end{array}$ \\
\hline Short-wave radiation scheme & Dudhia & $\begin{array}{l}\text { It is a simple downward integration of solar flux, } \\
\text { accounting for clear-air scattering, water vapor } \\
\text { absorption (Lacis and Hansen 1974), and cloud albedo } \\
\text { and absorption. It uses look-up tables for clouds from } \\
\text { Stephens (1978). }\end{array}$ \\
\hline Land surface process scheme & Noah land surface model & $\begin{array}{l}\text { Unified NCEP/NCAR/AFWA scheme with soil } \\
\text { temperature and moisture in four layers, fractional } \\
\text { snow cover, and frozen soil physics. }\end{array}$ \\
\hline Boundary layer process scheme & YSU & $\begin{array}{l}\text { Nonlocal-K scheme with explicit entrainment layer and } \\
\text { parabolic K profile in unstable mixed layer. }\end{array}$ \\
\hline Cumulus parameterization scheme & Kain-Fritsch & $\begin{array}{l}\text { It utilizes a simple cloud model with moist updrafts and } \\
\text { downdrafts, including the effects of detrainment, } \\
\text { entrainment, and relatively crude microphysics. }\end{array}$ \\
\hline
\end{tabular}

consists of 29 global climate models, and the dataset of Geophysical Fluid Dynamics Laboratory CM3 (GFDL-CM3) model is adopted in this study. It incorporates an atmospheric chemistry model within the fully interactive framework of the atmosphere, ocean, land, and sea-ice components and has four Representative Concentration Pathways (RCPs) scenarios such as RCP2.6, RCP4.5, RCP6.0, and RCP8.5. This study analyzed the energy flux under the RCP6.0 scenario; the $\mathrm{CO}_{2}$ concentration under this scenario ranks in the intermediate level, and it is incompatible with the actual situation in China. Since the dataset has been established and updated since July 1999, all the data needed in this study can be obtained, for example, the surface observation data and the remote sensing data.

\section{Methodology}

3.1. WRF Model. The Weather Research and Forecasting (WRF) Model is a next-generation mesoscale numerical weather prediction system designed to serve both atmospheric research and operational forecasting needs, and it features two dynamical cores, a data assimilation system and a software architecture allowing for parallel computation and system extensibility $[25,26]$. In addition, it serves a wide range of meteorological applications across scales ranging from meters to thousands of kilometers; therefore, it is suitable for any scale researches [27].

The WRF model is developed in two versions, one is for business, another one is for research, and this study adopts the latter one, namely, ARW (Advanced Research WRF), to carry out the relevant simulation. To simulate the energy flux distribution of near land surface more accurately, this study applies

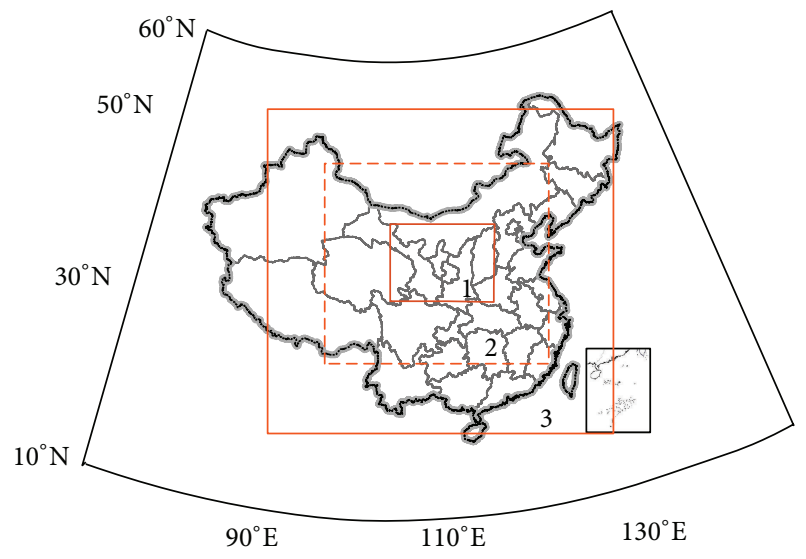

FIGURE 2: Schematic diagram of scheme design for three-layer nested WRF model.

three-layer nested structure including D01, D02, and D03, and the area ratio of three layers is $3: 2: 1$. The spatial resolution of output of D03 is set to $1 \mathrm{~km}$ (Figure 2). The air temperature, sea ice, and soil moisture data required by the model are updated every day.

The simulation was conducted with the land cover data and forcing data under two scenarios. Land cover dataset is from the United States Geological Survey's (USGS). The longwave radiation scheme and shortwave radiation scheme were RRTM and Dudhia, respectively; the boundary layer process scheme was YSU, and the land surface process scheme was NOAH Land surface model (Table 1). The simulation was implemented with the forcing data between January of 2010 and December of 2050. 
3.2. DLS Model. This study applies the DLS model to simulating the spatial distribution of land cover in the semiarid grassland area of China. It can carry out the simulation at two scales, the regional scale and the grid pixel scale, and predict the spatial distribution of land cover changes on the basis of land allocation among various sectors and spatial allocation for land-use changes between regions. The simulation includes four steps: firstly, it explores the driving mechanism of geophysical conditions and socioeconomic environment on the spatial distribution of land cover in the baseline year and extracts the significant driving factors which have obvious effects on the spatial distribution of land cover changes; secondly, the changing trends of the significant factors, which influence the spatial distribution of land cover, are predicted based on the historical characteristics and current status at the regional scale; thirdly, a proper scenario is identified to foresee the balances between the land supply and land demand; finally, the spatial allocation of land cover at $1 \mathrm{~km} \times$ $1 \mathrm{~km}$ grid pixel level is implemented, and then the spatial distribution map of land cover is finally generated $[28,29]$. The robust of the DLS model has been proved to simulate the land cover distribution, so it is adopted in this study [29].

3.3. Scenario Design. Based on the characteristics of socialeconomic development in the past 30 years, we design two kinds of social-economic development scenarios, that is, Rapid economic growth scenario (REG) and coordinated environmental sustainability scenario (CES). Those two scenarios are designed according to the economic development process and the structural characteristics in Loess Plateau combining the factors with the most possible changes such as population, factor endowments, and technological advances. It is on the basis of changing trend of land cover and socioeconomic factors in the past decades, but also, and the future socio-economic development trend. Under the REG scenario, it is assumed that the reforms will be put forward quickly and smoothly, the role of market in the allocation of resources will be enhanced obviously, structural adjustment will be vigorously promoted, and the economic growth pattern will make progress. CES scenario mainly considers the following aspects of changes: slower urbanization, slow recovering of the world economy, serious trade protection, slow export growth, higher international energy prices and restricted energy imports, slow progress in system reform and slow technological innovation, and efficiency improvement.

\section{Land Cover Changes from 2010 to 2050 in the Semiarid Grassland Area of China}

According to the land cover data of USGS in 2010, it is found that the main land cover in the semiarid grassland area of China is grassland and cropland, accounting for about $68.4 \%$ of the total area, and the following is barren or sparsely vegetated land, about $17.2 \%$. Based on the analysis of land cover in 2010, this study simulates the land cover of the semiarid grassland area of China from 2010 to 2050 under two kinds of scenarios by DLS model. The simulation results illustrate that the spatial distribution of land cover in the study area has no disruptive changes from 2010 to 2050, but the changing ratio will gradually slow down. The analysis on land cover change between different periods indicates that the conversion types are mainly dominated by the conversion between cropland and grassland. Under different scenarios, the tendency and scale of the major land cover changes vary in different ranges.

Under the CES scenario, the grassland cover shows an increasing trend. Although there will be increase in the forestry area in some parts of the study area to some extent, the total forestry area will show a slight decrease from 2010 to 2050. The harsh natural conditions restrict the forestry area expansion, and shrubland accounts for the largest part of the newly increased forest cover. Additionally, the CES scenario takes the policy of returning cropland to grassland or forestry area into account, which also promotes the growth of grassland area and the decrease in the cropland area. In the period of 2010-2030, the grassland will grow by $4.8 \%$, and it will increase $4.4 \%$ during the period of 2030-2050. Most of the increased grassland is converted from cropland and is distributed in the Shanxi Province, southern Shaanxi Province, southeast of Gansu Province and some areas of Ningxia. As for the cropland, it will reduce by $22.6 \times 10^{3} \mathrm{~km}^{2}$ from 2010 to 2030 , and by about $19.8 \times 10^{3} \mathrm{~km}^{2}$ in the period of 2030 2050 . Barren or sparsely vegetated land is another kind of land cover, most of which will be converted to grassland or shrubland in the north and middle of the semiarid grassland area of China due to ecological recovery construction (Figure 3). Another conversion from cropland is urban area expansion, it cannot be avoided during the process of urbanization, and the expanded area is mainly located in the surroundings of the cities.

The socio-economic development and rapid urbanization mean that more land will become urban. During the period of 2010-2050, there will be an increase of $5.3 \times 10^{3} \mathrm{~km}^{2}$ for urban area under the REG scenario, and the main land cover which is converted to urban area in the semiarid grassland area of China is cropland. Therefore, there is less cropland converted to grassland or forestry area. Compared to the CES scenario, the grassland will increase only by $23.3 \times 10^{3} \mathrm{~km}^{2}$ during the period of 2010-2030, with an increase of $4.2 \%$ until the period of 2030-2050. The expansion of grassland is mostly concentrated in the eastern part of Loess Plateau (Figure 3). On the contrary, most of the cropland is located in the southern part of the study area including the central and southern Shanxi Province, southern Shanxi Province, and southeastern Gansu Province. It is important to note that there are more water resources in the eastern and southern part of study area, which is beneficial for forest growing. Under the REG scenario, some areas of grasslands are degraded to bare land or are turned into cropland in the western part of the semiarid grassland area of China.

\section{Effects of Land Cover Conversion on Energy Balance in the Semiarid Grassland Area of China}

This study selects the latent heat flux and downward short wave radiation as the index then it estimates the energy 

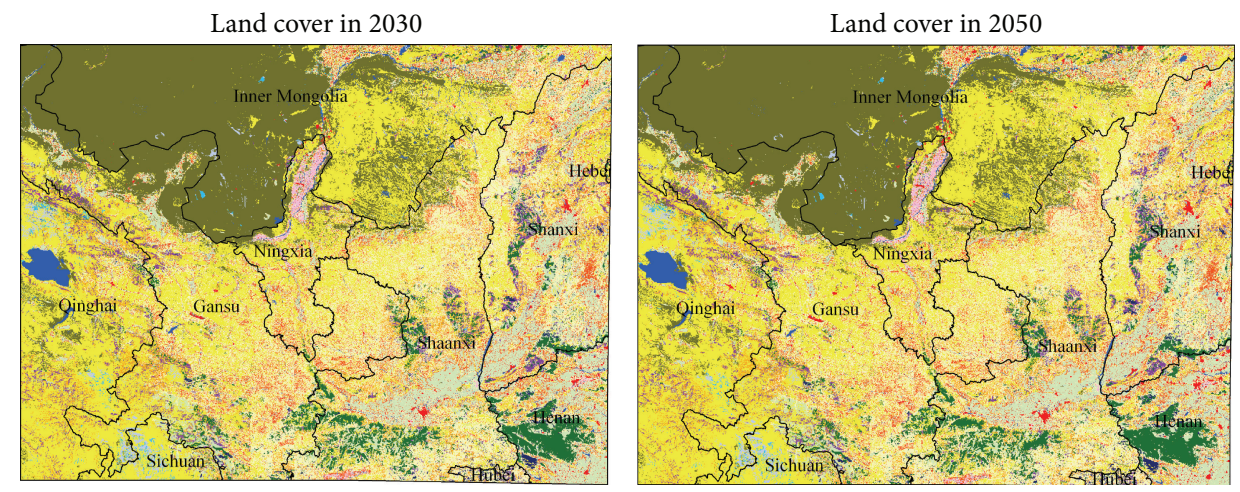

(a) REG scenario
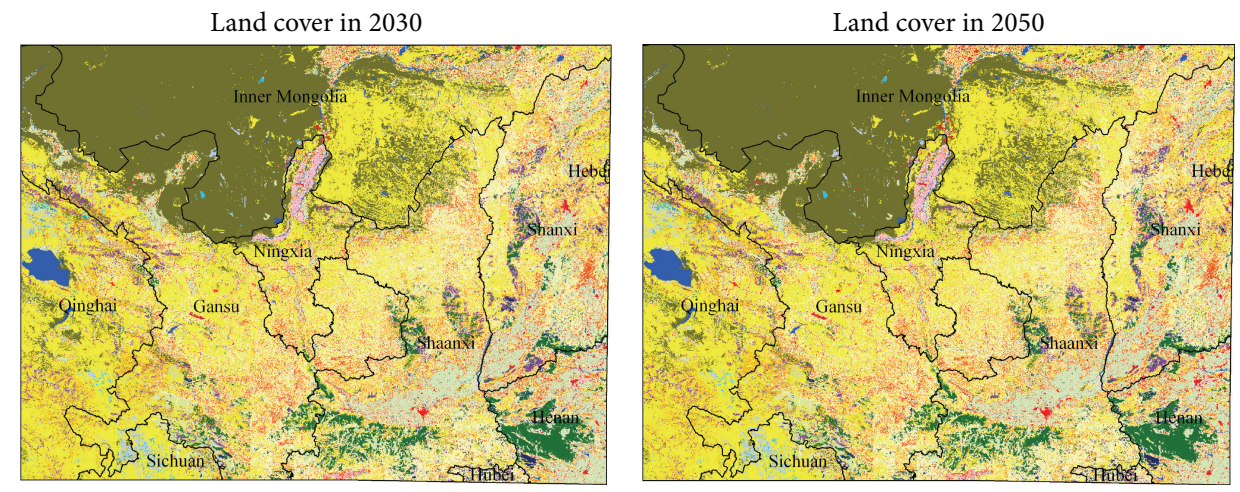

(b) CES scenario

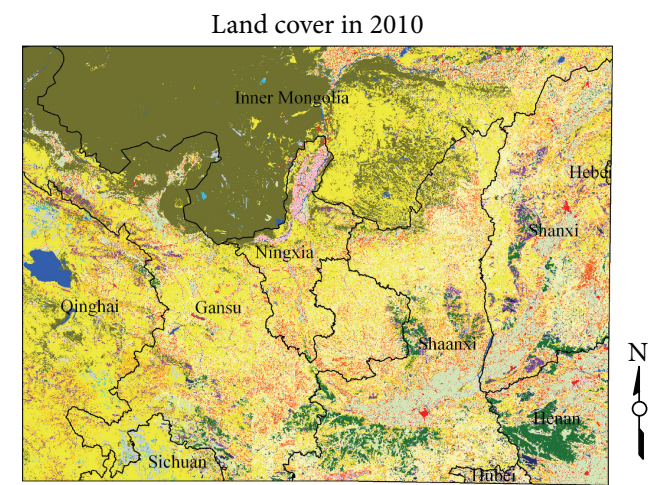

$(\mathrm{km})$

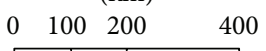

Urban and built-up land

Dryland cropland and pasture

Irrigated cropland and pasture

Mixed dryland/irrigated cropland and pasture

Cropland/grassland mosaic

Cropland/woodland mosaic

Grassland

Shrubland

Mixed shrubland/grassland

Savanna
Deciduous broadleaf forest Deciduous needleleaf forest Evergreen broadleaf forest Evergreen needleleaf forest Mixed forest

Water bodies

Herbaceous wetland

Wooded wetland

Barren or sparsely vegetated

Snow or ice

(c) Baseline Year

Figure 3: Land cover change under different scenarios from 2010 to 2050. 
TABLE 2: Statistics of heat flux and radiation of different land covers (unit: $\mathrm{W} / \mathrm{m}^{2}$ ).

\begin{tabular}{lcr}
\hline & Latent heat flux & Downward short-wave radiation \\
\hline Cropland and pasture & 24.9 & 279.6 \\
Grassland & 25.3 & 284.0 \\
Forestry area & 36.0 & 289.9 \\
Urban area & 15.0 & 295.0 \\
\hline
\end{tabular}

flux by the WRF model and summarizes the latent heat flux and downward short wave radiation of each type of land cover. The results indicate that different land covers have different energy fluxes, so the land cover conversion will produce different effects on regional environment and climate; however, the extent of their impacts and sensitive region has obvious temporal and spatial disparity. In addition, the statistics show that forestry area has highest latent heat flux with $36.0 \mathrm{~W} / \mathrm{m}^{2}$, while urban area has relative low latent heat flux which is $15.0 \mathrm{~W} / \mathrm{m}^{2}$ (Table 2).

5.1. Latent Heat Flux. This study estimates the monthly latent heat flux by the WRF model, and then calculates the annual average latent heat flux to analyze the effects of land cover conversion on the latent heat flux changes in the semiarid grassland area of China. The results show that the barren or sparsely vegetated land in the western parts of Inner Mongolia Autonomous Region and northern Shaanxi Province has lower latent heat flux, while it is higher in the southern areas which are mostly covered by grassland, shrubland, cropland, and pasture. Actually the forestry area also has higher latent heat flux; however, it has no obvious effects on energy flux since the forestry area in the study area is extremely small.

The annual average latent heat flux in the semiarid grassland area of China will not change obviously from 2010 to 2050 , with only $3.2 \mathrm{~W} / \mathrm{m}^{2}$ increment. However, there will be various climate effects in different areas from 2010 to 2050 in the semiarid grassland area of China (Figure 4). Due to the impacts of the policy of returning cropland to forestry area or grassland, the latent heat flux will increase in the middle part of Shanxi Province, southern part of Ningxia Province, southern, and southeast part of Gansu Province, with the increment ranging from $1.2 \mathrm{~W} / \mathrm{m}^{2}$ to $20.4 \mathrm{~W} / \mathrm{m}^{2}$. The grassland degradation could lead to the decrease of latent heat flux in the middle part of Inner Mongolia Autonomous Region, north of Ningxia Province, northwest of Shaanxi Province due to the conversion from grassland to barren or sparsely vegetated land, with a decrease of $3.2 \mathrm{~W} / \mathrm{m}^{2}$ (Figure 4).

To predict the energy balance in the future, this study simulates the energy flux under the two scenarios. The results illustrate that the latent heat flux under the CES scenario is higher than that of the REG scenario, this is because more ecological construction is conducted under the CES scenario which will produce more latent heat flux. It can be seen from Figure 4 that the two scenarios have similar spatial distribution of latent heat flux, but there are regional differences as well. The CES scenario has smaller areas within the range of
$4-14 \mathrm{~W} / \mathrm{m}^{2}$ especially in the central regions, but larger areas are within the range of $44-64 \mathrm{~W} / \mathrm{m}^{2}$.

5.2. Downward Short Wave Radiation. Downward short wave radiation is one of the significant factors influencing the energy balance of climate system. This study simulates the downward short wave radiation in different periods under the REG scenario and environment scenario from 2010 to 2050. The results show that the downward short wave radiation is weak in the Inner Mongolia Autonomous Region and the northern part of Shaanxi Province and Ningxia Hui Autonomous Region, while it is stronger in the southeastern area of Loess Plateau. This is because the northern part of Loess Plateau is covered mainly by the overlapped zone of the grassland and barren or sparsely vegetated land, while the land cover in the southeastern part is dryland cropland pasture. It can be seen from here that the policy of returning cropland to grassland will reduce the downward short wave radiation. However, different scenarios have different kinds of land cover changes, so the downward short wave radiation under two different scenarios has significant spatial and temporal disparity.

According to the statistical analysis of the downward short wave radiation at the grid scale, it can be found that the downward short wave radiation will have no obvious changes from 2010 to 2050 without regarding the scenarios, which will grow consistently from $280.4 \mathrm{~W} / \mathrm{m}^{2}$ to $282.1 \mathrm{~W} / \mathrm{m}^{2}$ under the CES scenario and that under the REG scenario will increase from $276.2 \mathrm{~W} / \mathrm{m}^{2}$ to $280.5 \mathrm{~W} / \mathrm{m}^{2}$ (Figure 5). Although the implementation of the policy of returning cropland to grassland can reduce the downward short wave radiation, the urban area expansion will lead to more downward short wave radiation, and that is why there is a higher increment of downward short wave radiation under the REG scenario. Compared to the downward short wave radiation under two different scenarios, it can be seen that it is higher under the REG scenario than that under the CES scenario in the period of 2010-2050. The spatial distribution of downward short wave radiation in 2030 and 2050 under the REG scenario shows that the area, whose downward short wave radiation is less than $265 \mathrm{~W} / \mathrm{m}^{2}$, is expanding especially in the north and middle region and the western part of the semiarid grassland area of China due to the ecological recovery (Figure 5). For example, the barren or sparsely vegetated lands are improved to be grassland gradually.

\section{Discussion and Conclusion}

This study applies the DLS model to simulate the land cover distribution from 2010 to 2050 under the CES scenario and 


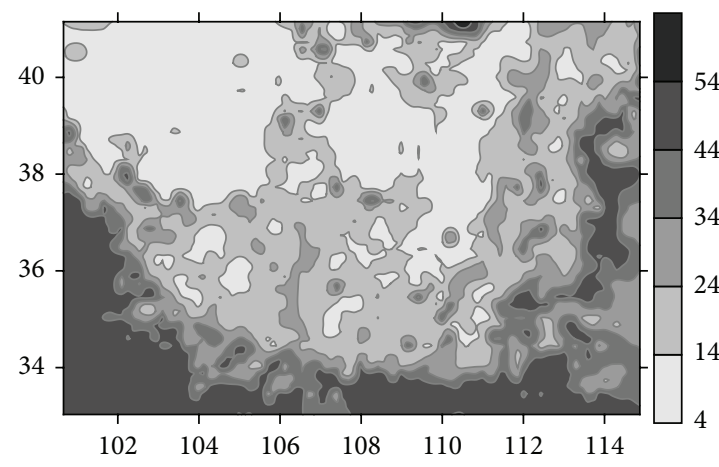

(a) REG scenario in 2030

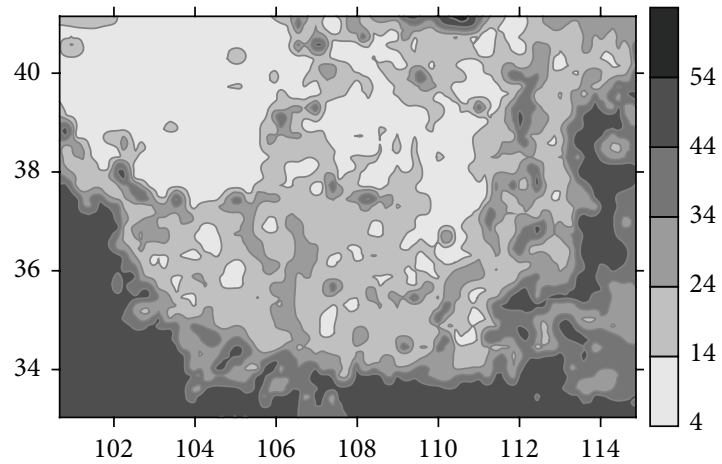

(c) REG scenario in 2050

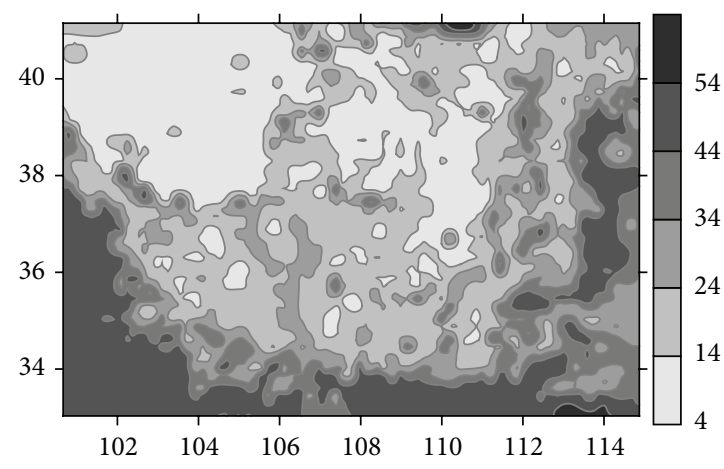

(b) CES scenario in 2030

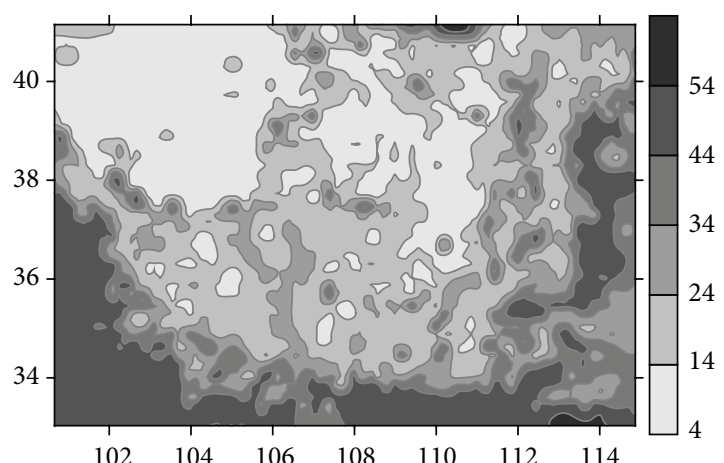

(d) CES scenario in 2050

FIGURE 4: Latent heat flux changes under different scenarios in 2030 and 2050 in the semiarid grassland area of China (unit: W/m²).

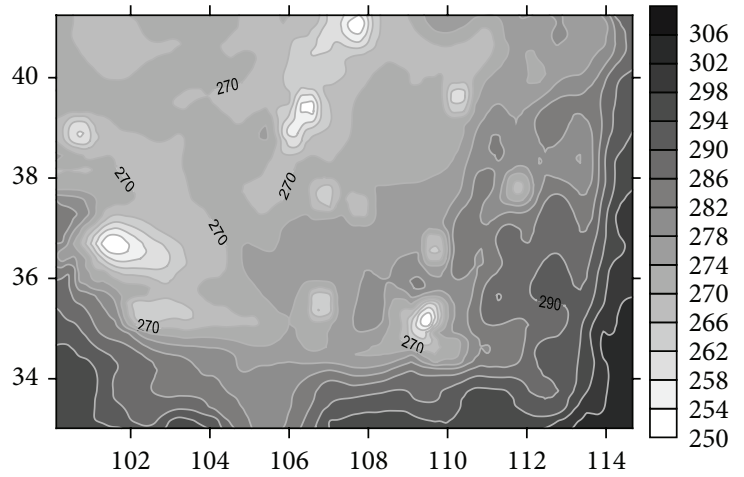

(a) REG scenario in 2030

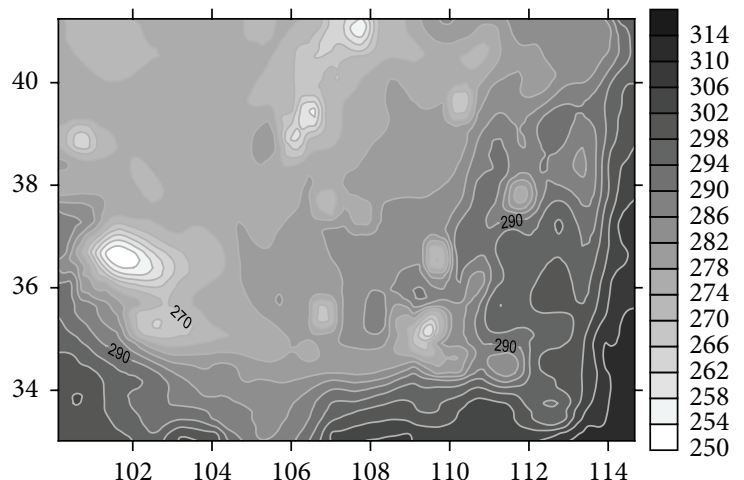

(c) REG scenario in 2050

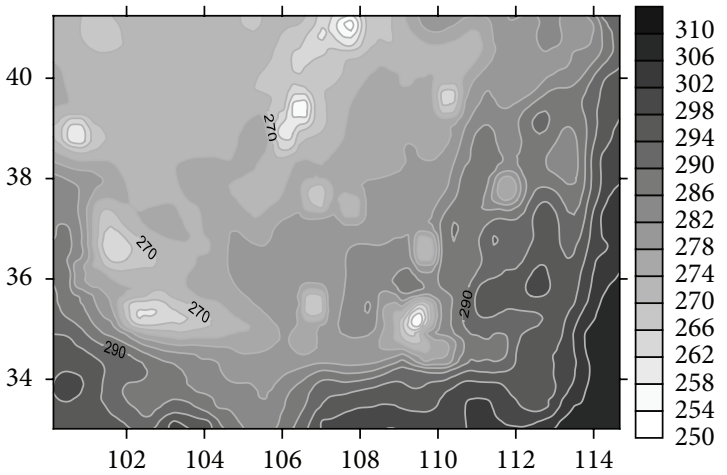

(b) CES scenario in 2030

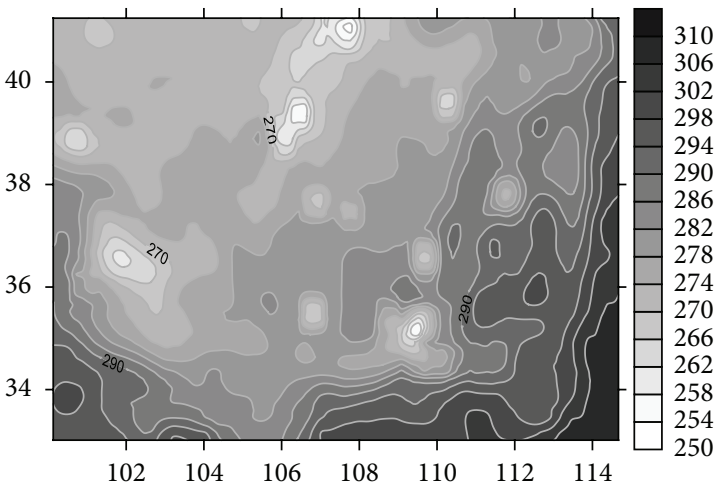

(d) CES scenario in 2050

FIGURE 5: Downward short wave radiation changes under different scenarios in 2030 and 2050 in the semiarid grassland area of China (unit: $\left.\mathrm{W} / \mathrm{m}^{2}\right)$. 
REG scenario and then analyzes the effects of land cover change on the regional energy balance in the semiarid grassland area of China through implementing the numerical simulation with the WRF model. Latent heat and radiation are the main factors influencing the energy balance, so this study selects two indexes including latent heat and downward short wave radiation to explore the energy balance in the study area. The conclusions are as follows.

(i) There will be no significant change in the spatial pattern of the land cover in the study area during 20102050. The changing ratio of all the land cover types will show a decreasing trend as the time passes. Under the CES scenario, the grassland shows an increasing trend, while the forest cover is shrinking because the harsh natural conditions restrict the forestry area expansion, and shrubland accounts for the largest percentage of the newly increased forest cover. Barren or sparsely vegetated land will be mainly converted to grassland or shrubland. During the period of 2010-2050, there will be an increase in urban area under the REG scenario, and the main land cover converted to urban area is cropland. Compared to the CES scenario, the rate of increase of grassland will be lower, and the expansion of grassland is mainly concentrated in the western part of Loess Plateau.

(ii) The simulation results indicate that there will be no obvious changes in energy flux of near surface under the CES scenario, and the latent heat flux and downward short wave radiation will all have small-scale increase. Therefore, the land cover conversion may have no great impact on climate in the coming forty years. However, the spatial disparity of energy flux is extremely significant. The policy of returning cropland and pasture to grassland or forestry area makes the latent heat increase to some extent, while the grassland degradation could lead to the decrease of latent heat due to the conversion from grassland to barren or sparsely vegetated land. As for the downward short wave radiation, it can be seen that it is higher under the REG scenario than that under the CES scenario in the study period. Urbanization and the decrease in forestry area will offset the energy flux reduction brought by grassland expansion.

Although we have carried out an estimation for the effects of land cover change on energy balance by the WRF model, there are certain limitations in our analysis. Firstly, there is uncertainty on the prediction of social-economic developments. This study applies the scenarios to predict the land cover change; however, we still can not ensure the accuracy of the prediction for the social-economic development. Secondly, there are various factors that influence the regional energy flux, but in this paper, only the land cover change is used to analyze its impacts on the regional energy flux.

\section{Conflict of Interests}

The authors declare that there is no conflict of interests regarding the publication of this paper.

\section{Acknowledgment}

This research was supported by the New Teachers' Scientific Research Program funded by Beijing Forestry University (no.
BLX2012044), the National Basic Research Program of China (973 Program) (no. 2010CB950900), and the Fundamental Research Funds for the Central Universities (no. TD2011-03). Data supports from Projects of the National Natural Science Foundation of China (no. 71225005; no. 41171434; no. 41071343) and the Exploratory Forefront Project for the Strategic Science Plan in IGSNRR, CAS, are also appreciated.

\section{References}

[1] J. A. Foley, R. DeFries, G. P. Asner et al., "Global consequences of land use," Science, vol. 309, no. 5734, pp. 570-574, 2005.

[2] IHDP, Urbanize and Global Environment Change, International Human Dimensions Programme on Global Environmental Change, Bonn, Germany, 2005.

[3] S. V. Russell, R. K. Thomas, R. E. David et al., "Impact of landuse change on climate," Nature, vol. 427, no. 6971, pp. 213-214, 2004.

[4] C. M. Paiva, G. B. Franca, W. T. Liu et al., "A comparison of experimental energy balance components data and SEBAL model results in Dourados, Brazil," International Journal of Remote Sensing, vol. 32, no. 6, pp. 1731-1745, 2011.

[5] J. Liu and X. Deng, "Influence of different land use on urban microenvironment in Beijing City, China," Journal of Food, Agriculture and Environment, vol. 9, no. 3-4, pp. 1005-1011, 2011.

[6] J. M. Bosch and J. D. Hewlett, "A review of catchment experiments to determine the effect of vegetation changes on water yield and evapotranspiration," Journal of Hydrology, vol. 55, no. 1-4, pp. 3-23, 1982.

[7] M. Liu, H. Tian, G. Chen, W. Ren, C. Zhang, and J. Liu, "Effects of land-use and land-cover change on evapotranspiration and water yield in China during 1900-2000," Journal of the American Water Resources Association, vol. 44, no. 5, pp. 1193-1207, 2008.

[8] J. I. López-Moreno, S. M. Vicente-Serrano, E. Moran-Tejeda, J. Zabalza, J. Lorenzo-Lacruz, and J. M. García-Ruiz, "Impact of climate evolution and land use changes on water yield in the ebro basin," Hydrology and Earth System Sciences, vol. 15, no. 1, pp. 311-322, 2011.

[9] K. L. Findell, E. Shevliakova, P. C. D. Milly, and R. J. Stouffer, "Modeled impact of anthropogenic land cover change on climate," Journal of Climate, vol. 20, no. 14, pp. 3621-3634, 2007.

[10] K. B. Wilson, P. J. Hanson, P. J. Mulholland, D. D. Baldocchi, and S. D. Wullschleger, "A comparison of methods for determining forest evapotranspiration and its components: sap-flow, soil water budget, eddy covariance and catchment water balance," Agricultural and Forest Meteorology, vol. 106, no. 2, pp. 153-168, 2001.

[11] W. Yao, M. Han, and S. Xu, "Estimating the regional evapotranspiration in Zhalong wetland with the Two-Source Energy Balance (TSEB) model and Landsat7/ETM+ images," Ecological Informatics, vol. 5, no. 5, pp. 348-358, 2010.

[12] R. A. Betts, P. D. Falloon, K. K. Goldewijk, and N. Ramankutty, "Biogeophysical effects of land use on climate: model simulations of radiative forcing and large-scale temperature change," Agricultural and Forest Meteorology, vol. 142, no. 2-4, pp. 216233, 2007.

[13] J. A. Foley, M. H. Costa, C. Delire et al., "Green surprise? How terrestrial ecosystems could affect earth's climate," Frontiers in Ecology and the Environment, vol. 1, pp. 38-44, 2003. 
[14] H. D. Matthews, A. J. Weaver, K. J. Meissner, N. P. Gillett, and M. Eby, "Natural and anthropogenic climate change: Incorporating historical land cover change, vegetation dynamics and the global carbon cycle," Climate Dynamics, vol. 22, no. 5, pp. 461479, 2004.

[15] A. J. Pitman, "The evolution of, and revolution in, land surface schemes designed for climate models," International Journal of Climatology, vol. 23, no. 5, pp. 479-510, 2003.

[16] Y. Q. Zheng, Y. P. Qian, M. Q. Miao et al., "The effects of vegetation change on regional climate I: simulation results," Acta Meteorologica Sinica, vol. 60, no. 1, pp. 1-16, 2002.

[17] T. Loridan, C. S. B. Grimmond, B. D. Offerle et al., "Local-scale Urban Meteorological Parameterization Scheme (LUMPS): longwave radiation parameterization and seasonality-related developments," Journal of Applied Meteorology and Climatology, vol. 50, no. 1, pp. 185-202, 2011.

[18] C. S. B. Grimmond, M. Blackett, M. J. Best et al., "The international urban energy balance models comparison project: first results from phase 1," Journal of Applied Meteorology and Climatology, vol. 49, no. 6, pp. 1268-1292, 2010.

[19] P. J. Lawrence and T. N. Chase, "Representing a new MODIS consistent land surface in the Community Land Model (CLM 3.0)," Journal of Geophysical Research G, vol. 112, no. 1, Article ID G01023, 2007.

[20] P. J. Lawrence and T. N. Chase, "Investigating the climate impacts of global land cover change in the community climate system model," International Journal of Climatology, vol. 30, no. 13, pp. 2066-2087, 2010.

[21] J. M. Clarke, "Effect of drought stress on residual transpiration and its relationship with water use of wheat," Canadian Journal of Plant Science, vol. 1, no. 3, pp. 695-702, 2000.

[22] S. Z. Kang, "Calculating method of potential atmospheric evaporation in the arid and semi-arid areas," Agriculture Research in the Arid Areas, vol. 1, no. 2, pp. 41-50, 1985 (Chinese).

[23] R. K. Vinukollu, E. F. Wood, C. R. Ferguson, and J. B. Fisher, "Global estimates of evapotranspiration for climate studies using multi-sensor remote sensing data: evaluation of three process-based approaches," Remote Sensing of Environment, vol. 115, no. 3, pp. 801-823, 2011.

[24] X. Gao, Y. Luo, W. Lin, Z. Zhao, and F. Giorgi, "Simulation of effects of land use change on climate in China by a regional climate model," Advances in Atmospheric Sciences, vol. 20, no. 4, pp. 583-592, 2003.

[25] M. A. Hernandez-Ceballos, J. A. Adame, J. P. Bolivar et al., "A mesoscale simulation of coastal circulation in the Guadalquivir valley (Southwestern Iberian Peninsula) using the WRF-ARW model," Atmospheric Research, vol. 124, pp. 1-20, 2013.

[26] M. Mohan and S. Bhati, "Analysis of WRF model performance over subtropical region of Delhi, India," Advances in Meteorology, vol. 2011, Article ID 621235, 13 pages, 2011.

[27] R. J. Qu, X. L. Cui, H. M. Yan et al., "Impacts of land cover change on the near-surface temperature in the North China plain," Advances in Meteorology, vol. 2013, Article ID 409302, 12 pages, 2013.

[28] X. Deng, Q. Jiang, H. Su, and F. Wu, “Trace forest conversions in Northeast China with a 1-km area percentage data model," Journal of Applied Remote Sensing, vol. 4, no. 1, Article ID 041893, 13 pages, 2011.

[29] X. Deng, Q. Jiang, J. Zhan, S. He, and Y. Lin, "Simulation on the dynamics of forest area changes in Northeast China," Journal of Geographical Sciences, vol. 20, no. 4, pp. 495-509, 2010. 

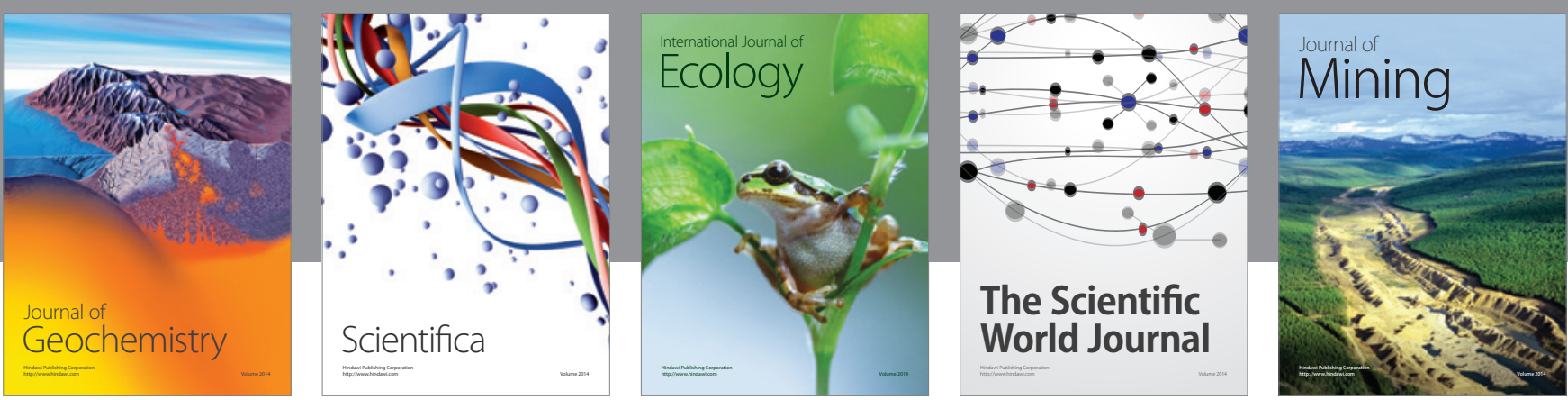

The Scientific World Journal
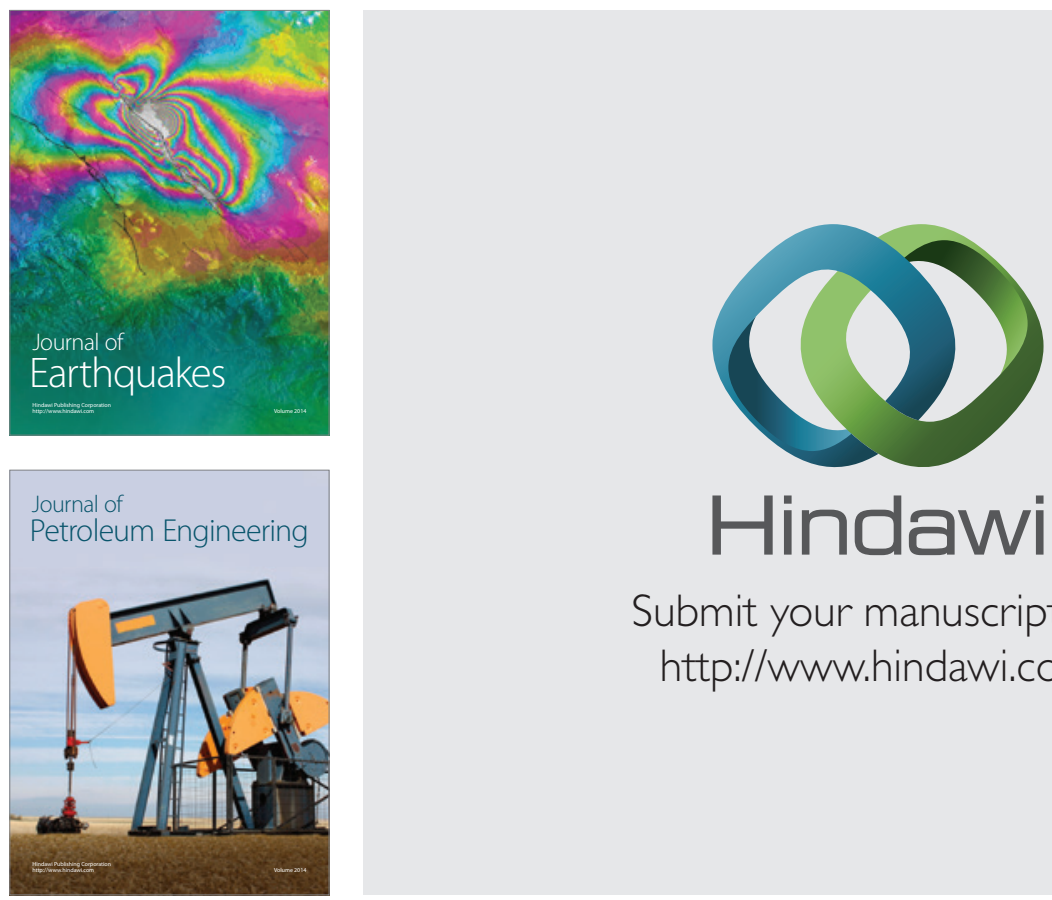

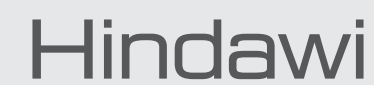

Submit your manuscripts at

http://www.hindawi.com
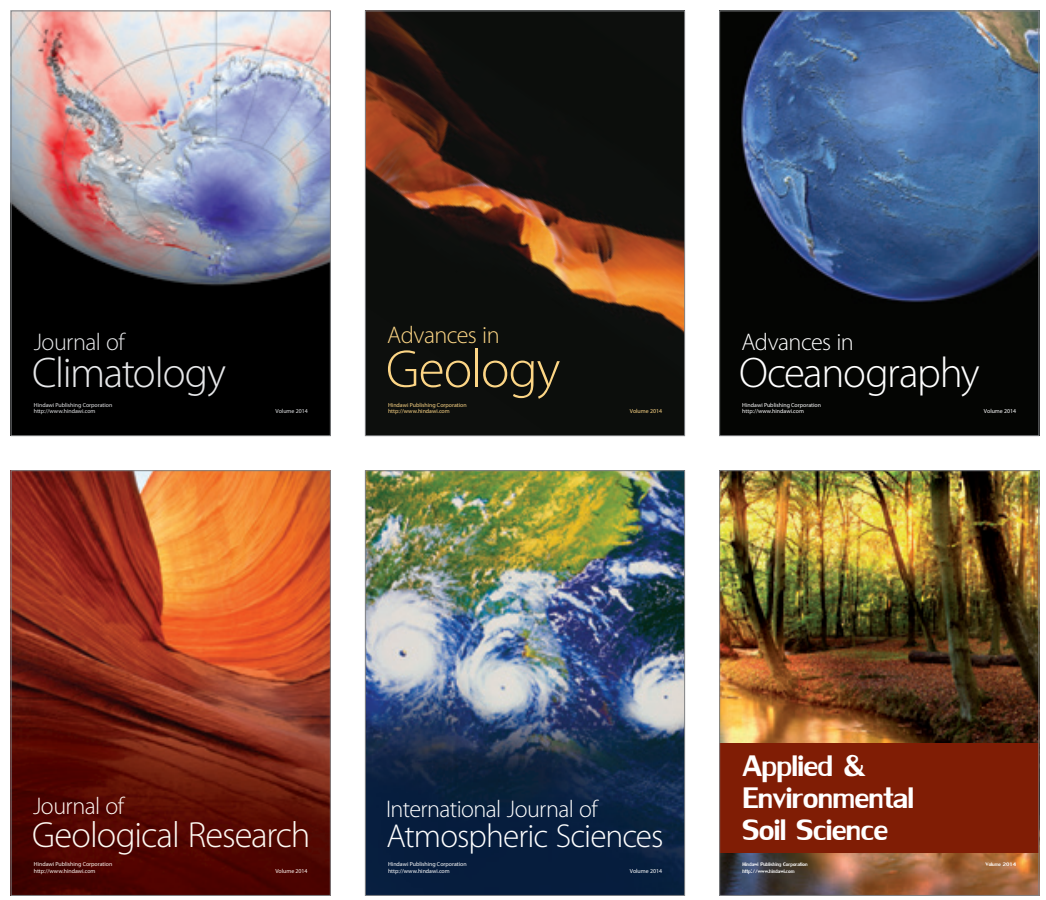
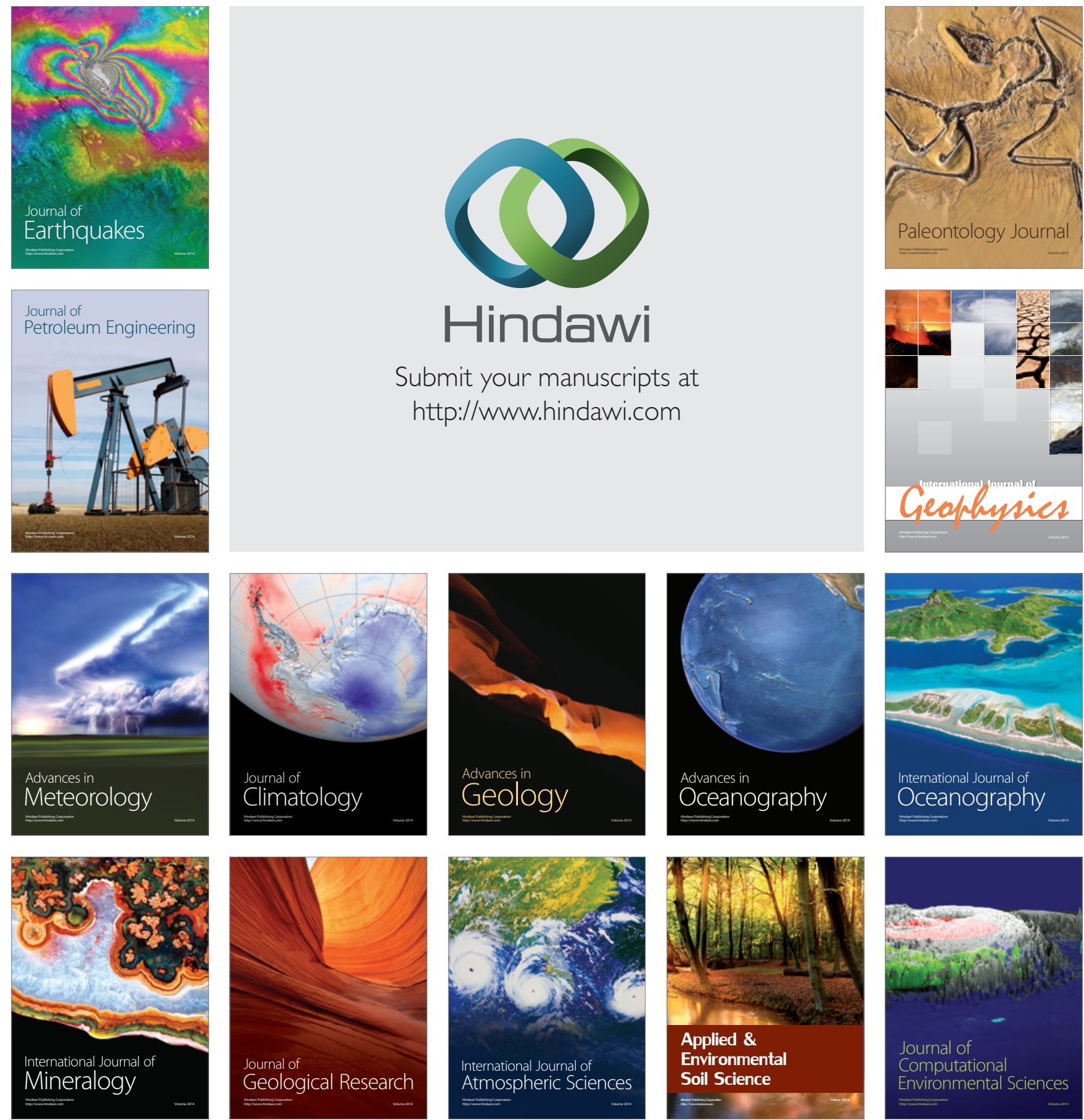